\title{
TUDO TEM UM PREÇO? A COMERCIALZAÇÃO DA EXPERIÊNCIA DE APRISIONAMENTO
}

Clara Luisa Silva ${ }^{1}$

Luiz Alex Saraiva ${ }^{2}$

\section{RESUMO}

O objetivo neste ensaio fotográfico é representar, mediante um conjunto de fotografias, o argumento de que os espaços sociais do claustro, por meio de seus elementos concretos e simbólicos, são redefinidos e reapropriados de modo a apresentar a ideia da condição de aprisionamento como um produto cultural. Aspectos que se relacionam ao escopo da arquitetura, gastronomia, artes visuais são redimensionados e sustentam um processo em que os espaços de claustro são requalificados e ressignificados, alinhando-se a um movimento de uso da cultura como instrumento de desenvolvimento dos negócios, precisamente, aos negócios que tangem ao mercado do turismo.

Palavras-chave: Instituições totais. Conventos. Equipamentos culturais.

\section{EVERYTHING HASAPRICE?THECOMMERCIALIZATIONOFIMPRISIONMENTEXPERIENCE}

\section{ABSTRACT}

\footnotetext{
11 Doutoranda em Administração pela Universidade Federal de Minas Gerais. Professora EBTT do Instituto Federal de São Paulo.

22 Doutor em Administração pela Universidade Federal de Minas Gerais. Professor Adjunto da Faculdade de Faculdade de Ciências Econômicas da Universidade Federal de Minas Gerais.
} 
The aim, in this essay, is to represent, through a set of photographies, the argument that the social spaces of the prision, through its concrete and symbolic elements are defined and appropriate in order to present the idea the imprisonment condition as a cultural product. Aspects that relate to the scope of architecture, gastronomy, visual arts are sized and sustain a process in which the prision is qualified and meanings, aligning themselves to movement of use of a culture as business development tool precisely to businesses that concern the tourism market.

Key-words: Total institutions. Convents. Cultural equipament.

\section{TODO TIENE UN PRECIO? LA COMERCIALIZACIÓN DE LA EXPERIÊNCIA DE ENCARCELAMIENTO}

\section{RESUMEN}

El objetivo de este ensayo, representado por un conjunto de fotografías, es argumentar que los espacios sociales del claustro, a través de sus elementos concretos y simbólicos son redefinidos y reapropiados con el fin de presentar la condición de encarcelamiento como un producto cultural. Aspectos relacionados con el ámbito de la arquitectura, la gastronomía, las artes visuales son replanteados y sostienen un proceso en que los espacios de claustro son recualificados y resignificados, alineándose a un movimiento de uso de la cultura como herramienta de desarrollo de negocios, precisamente, a los negocios que se refieren al mercado turístico.

Palabras clave: Instituciones totales. Conventos. Equipamentos culturales. 


\section{TUDO TEM UM PREÇO? A COMERCIALIZAÇÃO DA EXPERIÊNCIA DE APRISIONAMENTO}

Sítio das espacialidades humanas, fala-se de lugar como algo que incorpora o cotidiano, realidade social marcada pelos traços do presente e da história, o que pode colocar o ser humano diante do desamparo, mas que, ao mesmo tempo, pode lhe fornecer algo para refazer, para re-juntar, no con-texto, suas fragmentações na história e nas geografias propriamente ditas (VALADARES, 2000).

O lugar, como um produto social, nunca está "vazio" porque abarca significados para os sujeitos que nele estabeleceram suas ações (LEFEBVRE, 1991). É, por assim dizer, "espaço preenchido" por pessoas, práticas, experiências, objetos e representações (GIERYN, 2000), no qual são inscritas e reproduzidas funções materiais de valores sociais (FISCHER, 1994).

Por se construir em um quadro de múltiplas possibilidades de ação humana, o lugar não se apresenta como uma realidade passiva, absoluta e estática. Ao contrário, a compreensão de um dado espaço social passa por um referencial de dinamicidade, haja vista o contínuo devir que caracteriza as relações entre os elementos concretos e de construção simbólica de um lugar (CHANLAT, 1996; STEPHENSON, 2010).

O lugar pelo qual nos interessamos neste ensaio fotográfico é o contexto das instituições totais, de modo geral. Lugar em que os sujeitos, geralmente em grande quantidade, vivem fechados, separados da sociedade mais ampla, tendo sua vida formalmente administrada por considerável período de tempo. Esta é uma primeira definição de instituição total. Falar de fechamento, no âmbito dessas organizações totais, significa fazer alusão ao fato de que o "[...] seu caráter total é simbolizado pela barreira à relação social com o mundo externo e por proibições à saída que muitas vezes estão incluídas no esquema físico [...]" (GOFFMAN, 1961, p. 16). Fechamento aqui está relacionado à ideia de aprisionamento, e por extensão, à existência de uma espécie de poder modelador e repressivo que controla, 
por completo, os sujeitos - em suas expressões concretas (movimentos do corpo) e subjetivas - que vivem em asilos, orfanatos, hospitais psiquiátricos, prisões, quarteis, comunidades em navios em alto mar, mosteiros, conventos e outros claustros, todos exemplos de instituições totais.

De modo específico, nossa inquietação repousa no processo de requalificação de muitos conventos e mosteiros, claustros para instrução para os religiosos nos quais eles se refugiam do mundo. Quando mencionamos "requalificação", intentamos fazer referência a novos usos de tais espaços sociais, que passam a abrigar, por exemplo, museus, hotéis, restaurantes, centros culturais. Em todos estes processos de requalificação, o destaque parece ser conferido à experiência do aprisionamento, de estar em um espaço social em que religiosos estão (ou estavam) enclausurados.

Isto posto, o que buscamos defender e, ainda representar mediante um conjunto de fotografias, é o argumento de que os espaços sociais do claustro, por meio de seus elementos concretos e simbólicos, são redefinidos e reapropriados de modo a apresentar a ideia da condição de aprisionamento como um produto cultural.

\section{Os retratos e escritos dos claustros: novos (e velhos) usos e ressignificações}

\section{A história recontada nas paredes e nos folhetos}

Convento de Santa Catalina e Claustros del Pilar foram os dois espaços sociais visitados, na cidade de Buenos Aires, a fim de cumprir o objetivo deste ensaio fotográfico. Não obstante a sua construção tenha se iniciado em 1717, foi em 1745 que ocorreu a inauguração do Convento de Santa Catalina, o primeiro monastério de monjas da capital argentina, da Segunda Ordem Dominicana, que se dedicavam a uma vida contemplativa baseada na oração e na penitência. Em 1974, as monjas deixaram o convento para se instalarem na região de San Justo. No ano seguinte, o monastério foi considerado 
Monumento Histórico Nacional. Os trabalhos de restauração e, por conseguinte, de preparação do espaço para a visitação de turistas e fieis, se iniciaram em 2001.

No que diz respeito aos Claustros del Pilar, o início de sua construção, juntamente com a Basílica Nuestra Señora del Pilar, se deu em 1745, por iniciativa dos grupo de Frades Recoletos Descalços. Os claustros são uma parte anexa ao espaço da igreja e, na época de sua fundação, era um dos acessos ao campanário, ao púlpito, e ao próprio cemitério da Recoleta, que fica próximo à edificação. 0 espaço era também usado como cela pelos religiosos enquanto se construía o convento. Os Claustros del Pilar foram abertos ao público em 1997. Neste espaço podemos encontrar distintas obras de arte, livros, vestes religiosos e artefatos que aludem à fé católica e ao cotidiano no convento.

\section{O ESPETÁCULO DAS RUÍNAS}

As ruínas de um espaço podem ser concebidas como elementos concretos, frutos da intervenção humana no passado (CHOAY, 2001) e, assim, buscar a preservação destas ruínas significa também buscar a preservação das marcas do passado e das sociabilidades que o mesmo engendra (MENEGUELLO, 2008). No Convento de Santa Catalina e Claustros del Pilar, a conformação do valor simbólico destes espaços para o turismo se orienta pela exploração características primeiras dos edifícios, aqui delimitadas pelo traço singular de determinado estilo arquitetônico (conforme a figura 1), bem como os aspectos que surgem com o passar do tempo, tais como rachaduras e manchas no chão e nas paredes (figuras 2, 3 e 4). 


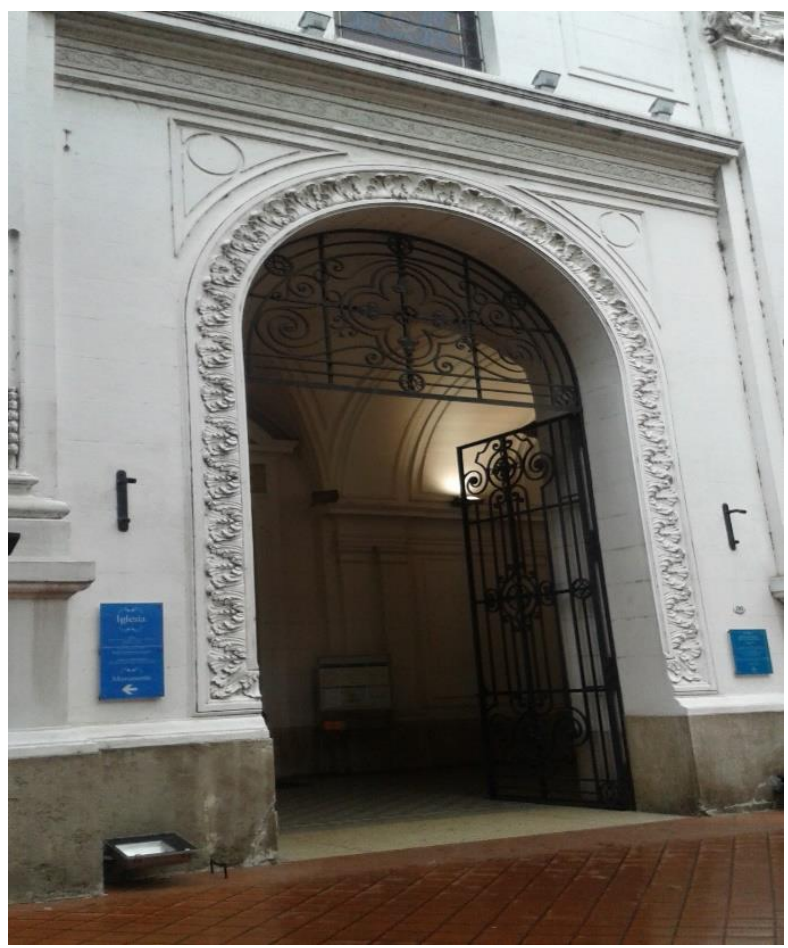

Figura 1: Entrada do Convento de Santa Catalina

Fonte: Acervo dos autores.

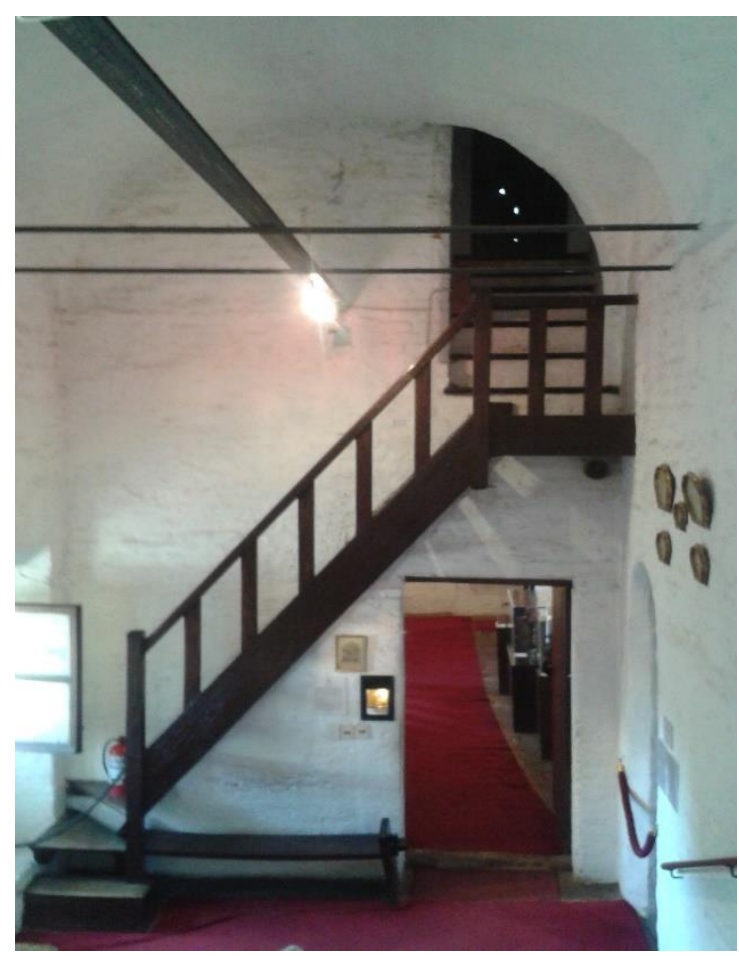

Figura 2: Sala de acesso aos Claustros del Pilar

Fonte: Acervo dos autores. 


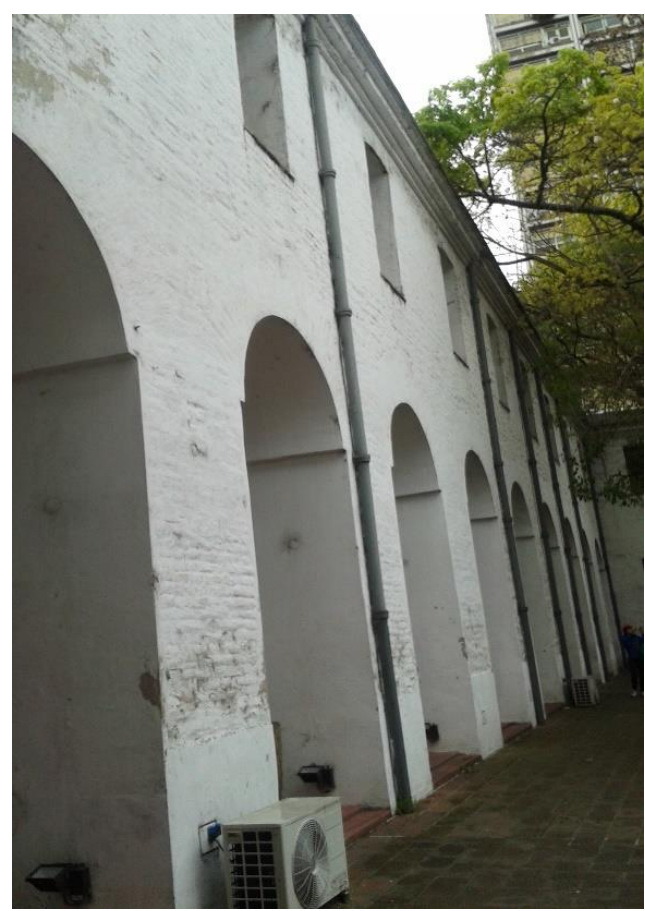

Figura 3: Paredes do Convento de Santa Catalina

Fonte: Acervo dos autores.

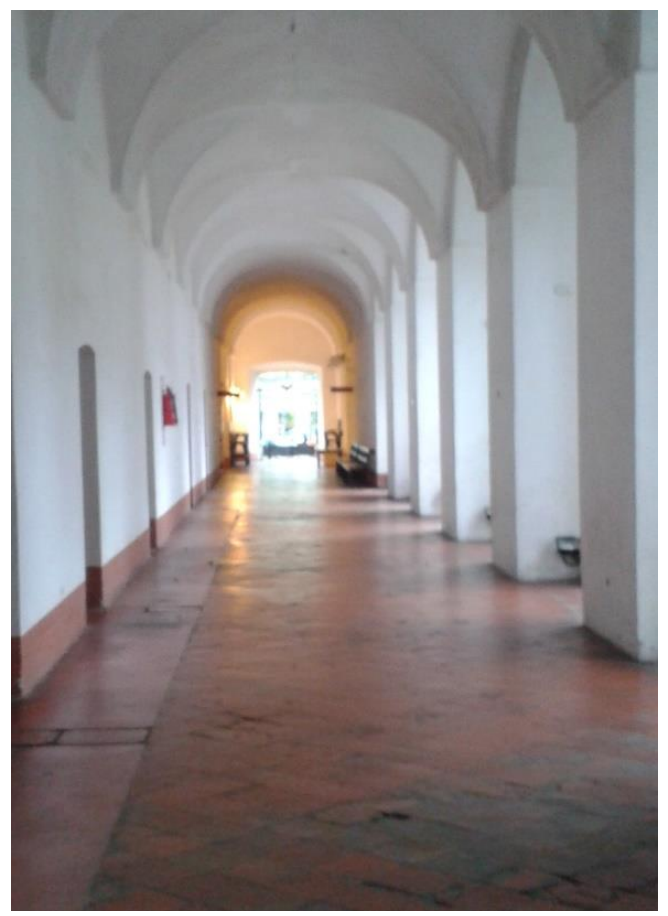

Figura 4: Marcas do tempo em Santa Catalina

Fonte: Acervo dos autores. 


\section{O LUGAR DO MOBILIÁRIO}

A disposição da mobília no convento parece ser feita para reforçar um estilo de vida próprio dos sujeitos que viviam no claustro, conforme pode ser visto na figura 5.

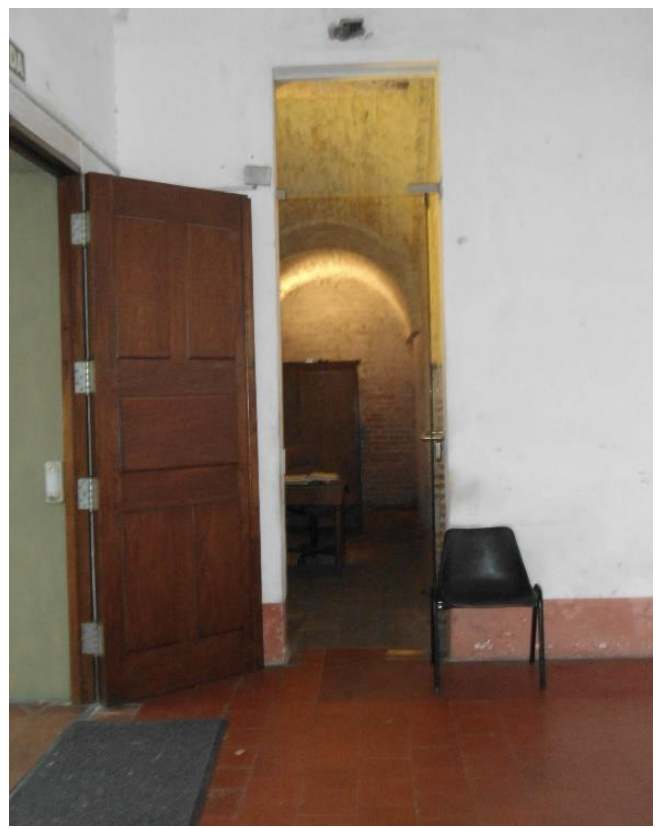

Figura 5: Disposição de mobiliário no Convento Santa Catalina

Fonte: Acervo dos autores.

Os espaços são compostos com poucos móveis, bastante simples (figura 6), representando os votos de pobreza feitos pelos padres e freiras que ali habitaram. 


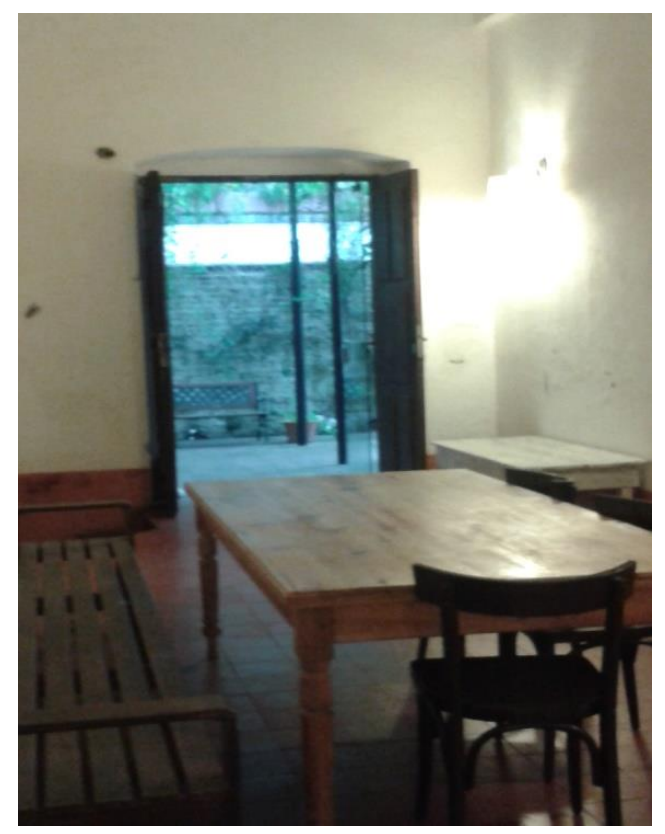

Figura 6: Simplicidade do mobiliário no Convento Santa Catalina Fonte: Acervo dos autores.

\section{OS SABORES NO CONVENTO}

A idéia de que o Convento de Santa Catalina foi redefinido para se tornar um espaço turístico fica mais clara quando se observa que, no âmbito do claustro, existe um restaurante aberto ao público. 0 imaginário da simplicidade que norteia a condição de clausura dos religiosos materializa-se nos elementos do espaço físico em que são realizadas as refeições (figura 7), e ainda nas próprias opções de pratos servidos no tal restaurante (figura 8). 


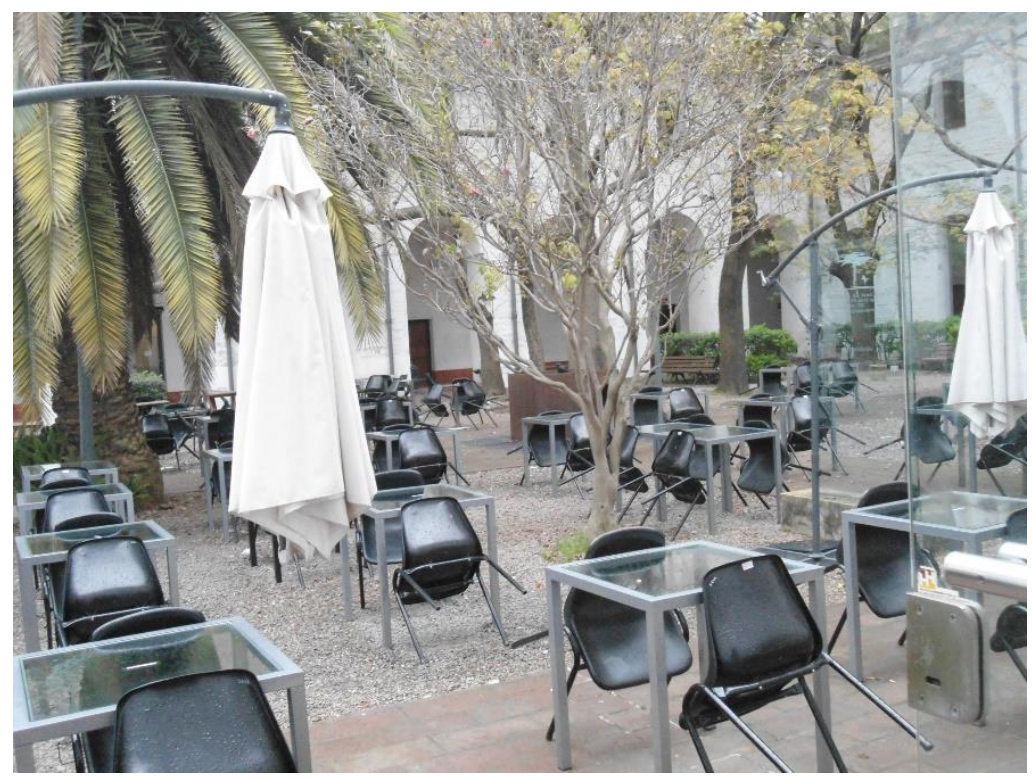

Imagem 7: Espaço do restaurante no Convento Santa Catalina

Fonte: Acervo dos autores.

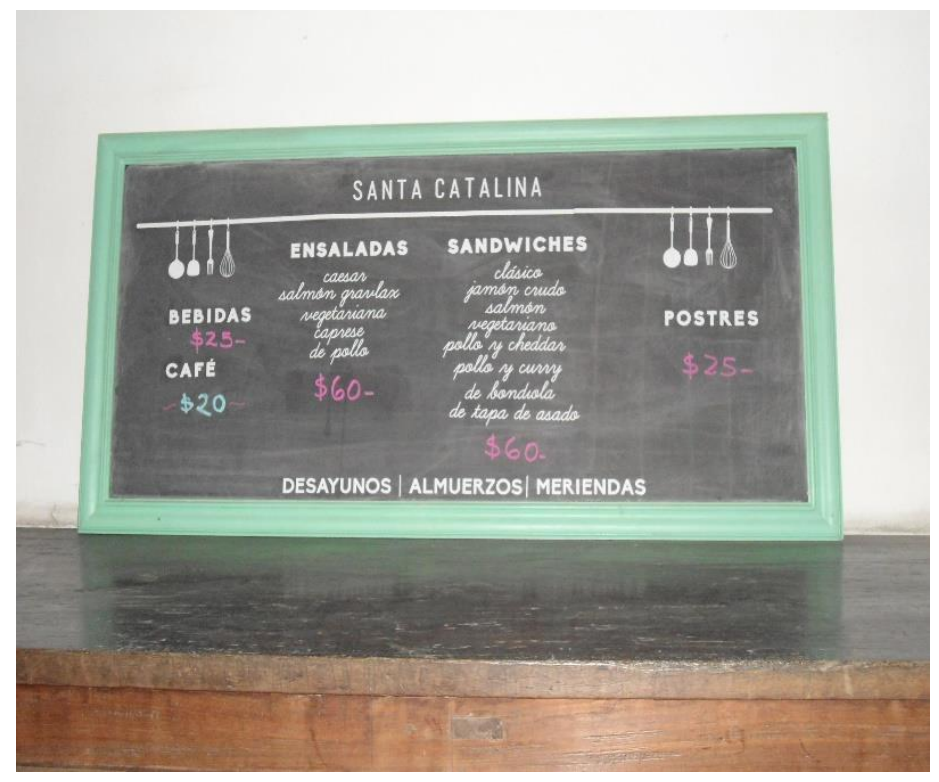

Imagem 8: Cardápio do restaurante no convento

Fonte: Acervo dos autores. 


\section{A VALORIZAÇÃO DA ARTE “POPULAR”}

Além dos artefatos do cotidiano de um espaço de recolhimento de religiosos, nos Claustros del Pilar se encontram objetos produzidos por artistas da comunidade do entorno, numa referência a um processo que podemos identificar como uma busca pelo exótico ou pelo que encerra características regionais. A figura 9 apresenta quatro ilustrações feitas a partir de um modo diverso ao das maiorias das pinturas sacras, isso no que se refere tanto ao traçado quanto aos materiais utilizados.

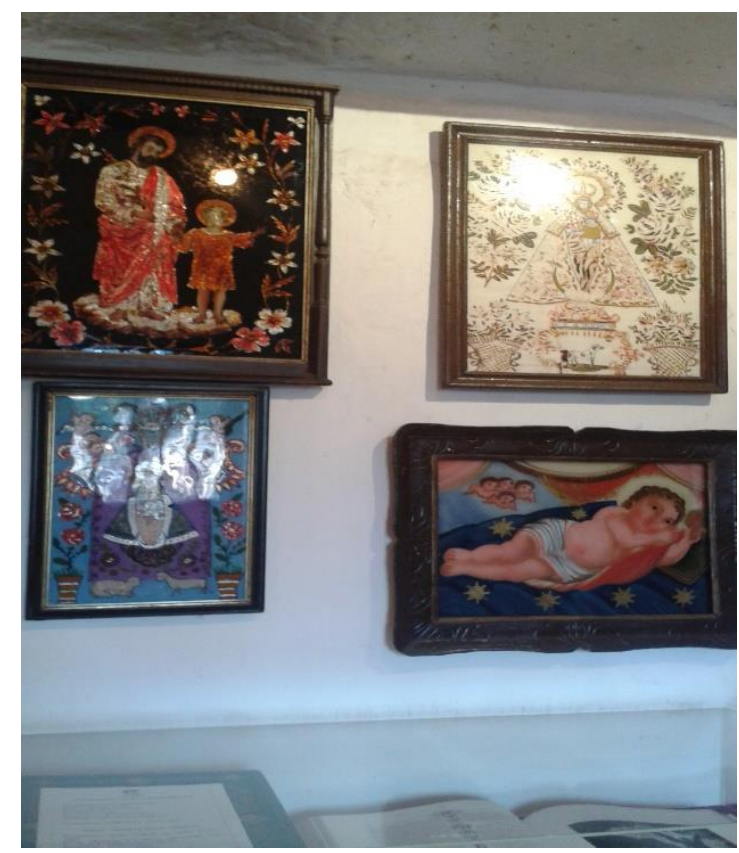

Imagem 9: Obras de arte feitas por artistas da região

Fonte: Acervo dos autores.

\section{A VALORIZAÇÃO DAS ORIGENS E O REDIMENSIONAMENTO DAS TRADIÇÕES RELIGIOSAS}

O cotidiano de quem vive em um convento abarca a prática da confissão, prática esta que se confunde com uma espécie de mecanismo de poder usado para "conhecer" a conduta íntima dos sujeitos e impor-lhes obediência aos preceitos morais convencionalmente aceitos. 0 espaço para a prática da confissão incorpora aqui um sentido para além da 
representação da vida monástica e ali está disposto, concreta e simbolicamente, para estimular que os visitantes aproveitem também para se confessar nos horários determinados (figura 10). 0 que percebemos é a perpetuação, em espaço cultural, de um regime de poder - saber - prazer, isto é, o corpo e suas práticas sendo o objeto do saber e alvo de um investimento político que lhes são próprios (FOUCAULT, 1988).

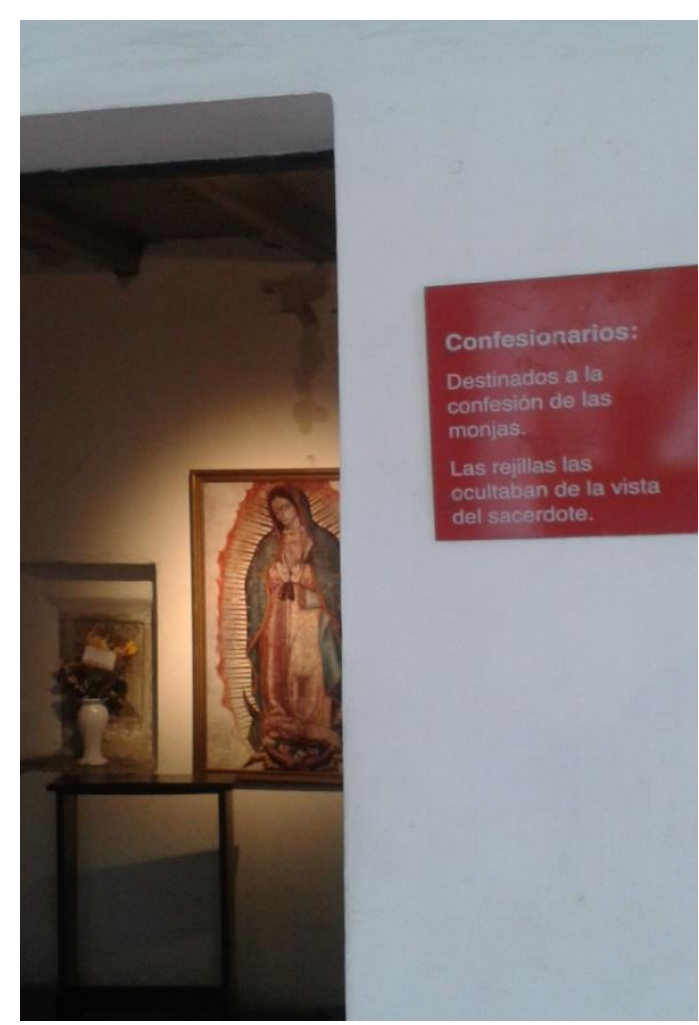

Imagem 10: Confessionário no Convento de Santa Catalina

Fonte: Acervo dos autores.

\section{O ESPETÁCULO DO APRISIONAMENTO: VENDENDO A EXPERIÊNCIA DE ESTAR NO CONVENTO}

As representações do "estar enclausurado" ou "estar aprisionado" aparecem em elementos concretos como as grades das janelas (figura 11), as chaves do convento desde a sua fundação (figura 12), como se percebe em uma visita aos Claustros del Pilar. 


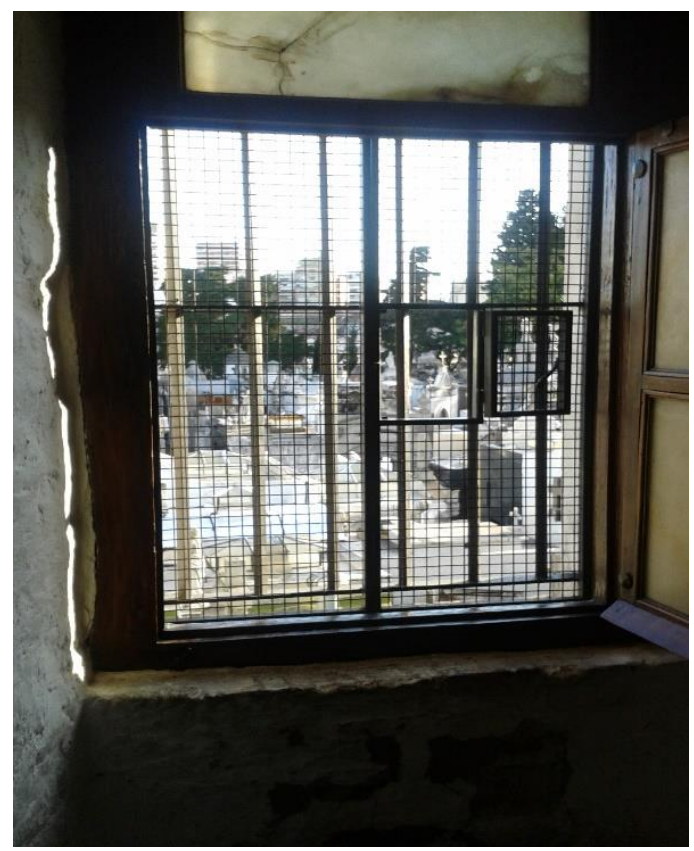

Figura 11: Claustros del Pilar

Fonte: Acervo dos autores.

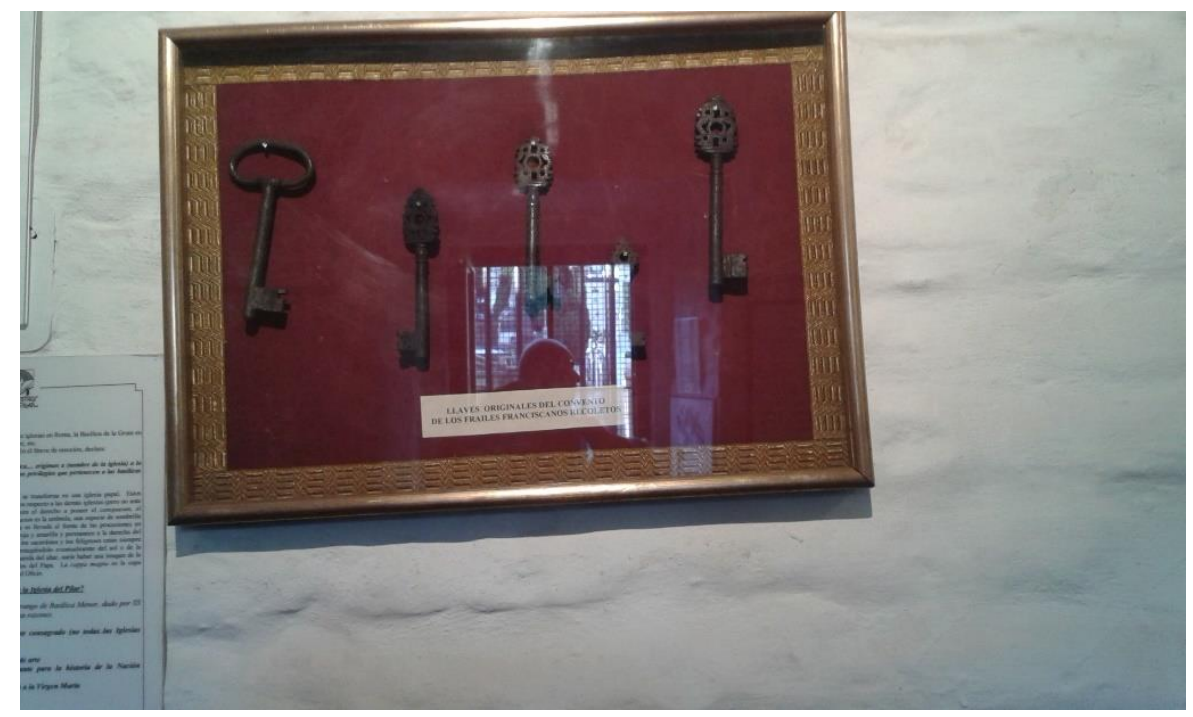

Figura 12: As primeiras chaves do convento expostas nos Claustros Del Pilar

Fonte: Acervo dos autores.

A ideia do aprisionamento é delineada em um espetáculo que tem dia e horário específicos. No Convento de Santa Catalina, por exemplo, os espaços próximos ao conjunto de celas das religiosas (figura 13) são restritos (figura 14) e podem ser visitados apenas 
na presença de um guia e evidentemente logo após o pagamento de uma soma de dinheiro que corresponde a 25 reais (figura 15).

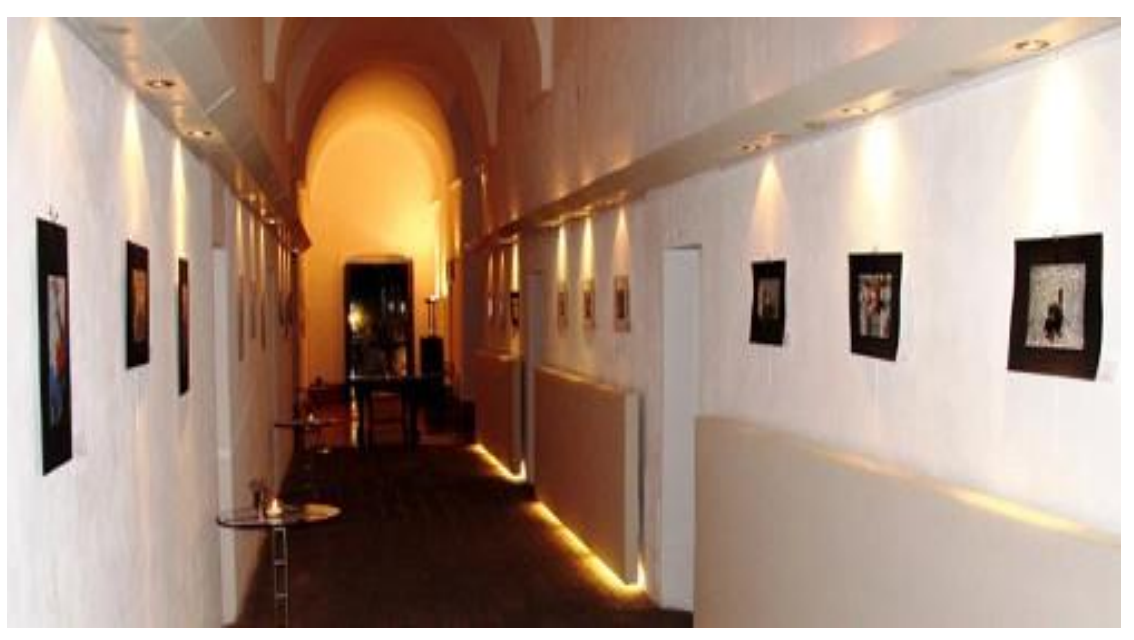

Figura 13: Espaço das celas do convento

Fonte: Acervo dos autores.

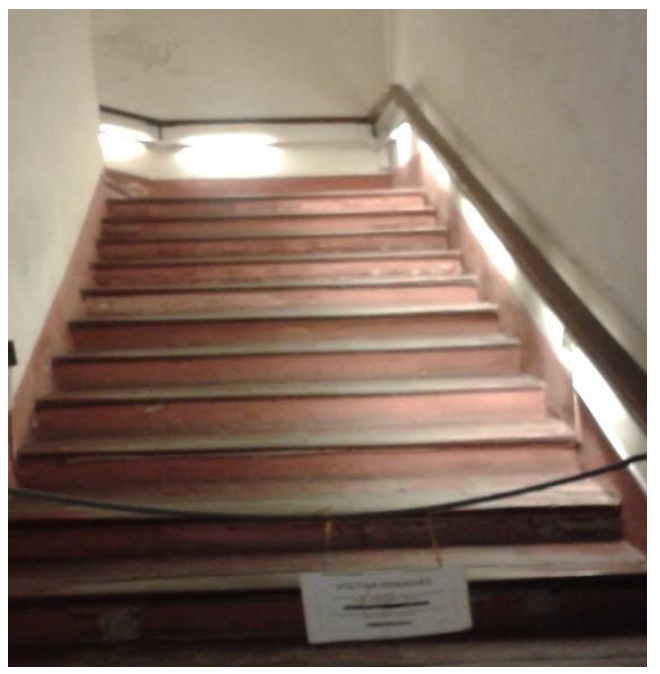

Figura 14: Espaço da visita guiada

Fonte: Acervo dos autores. 


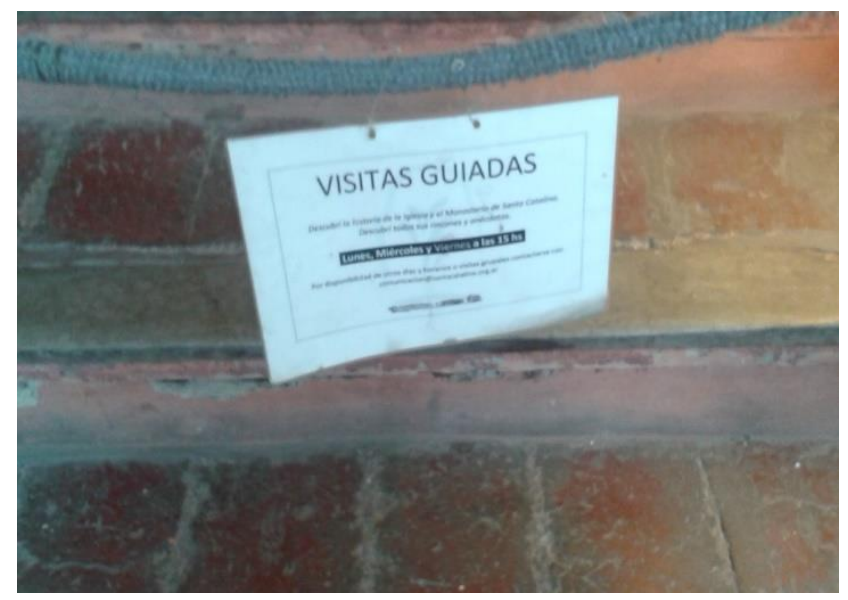

Figura 15: Informações da visita guiada

Fonte: Acervo dos autores.

\section{O CONVENTO COMO UM ESPAÇO DE COMPRAS}

Convento: espaço de reclusão, de oração - e, também, de compras. Nos Claustros del Pilar, o comércio de artigos religiosos pode ser feito tanto no pátio da igreja que fica no mesmo edifício do convento, quanto em espaço chamado Santería del Pilar, uma pequena loja (figura 16).

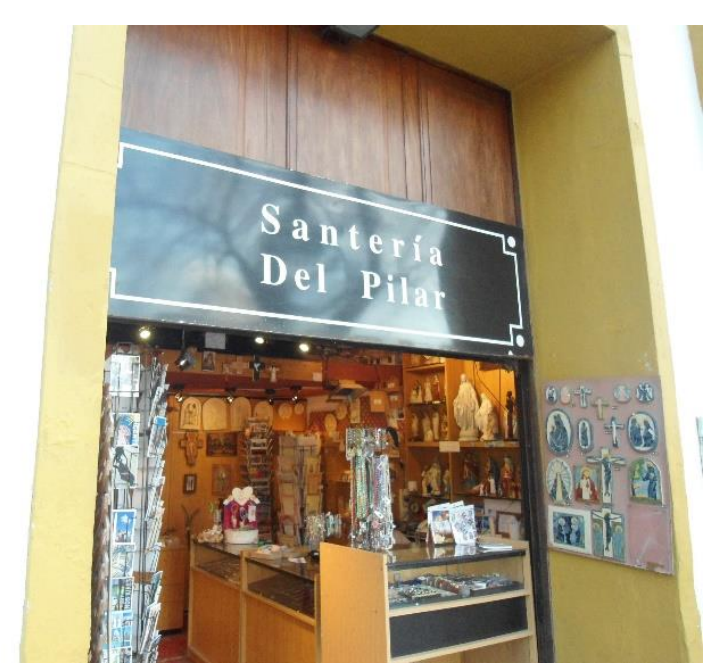

Figura 16: Loja 
Fonte: Acervo dos autores.

\section{A LINGUAGEM PARA QUEM CONSOME}

O ordenamento dos espaços consiste na disposição de elementos concretos, na forma de artefatos do cotidiano do convento, mas abarca, principalmente, a organização do lugar em uma dimensão discursiva. Precisamente, o Convento de Santa Catalina foi reconstruído de modo a orientar o acesso do público que visita. Mapas e placas de indicação como os das fotografias 17 e 18 são vistos por toda a edificação.

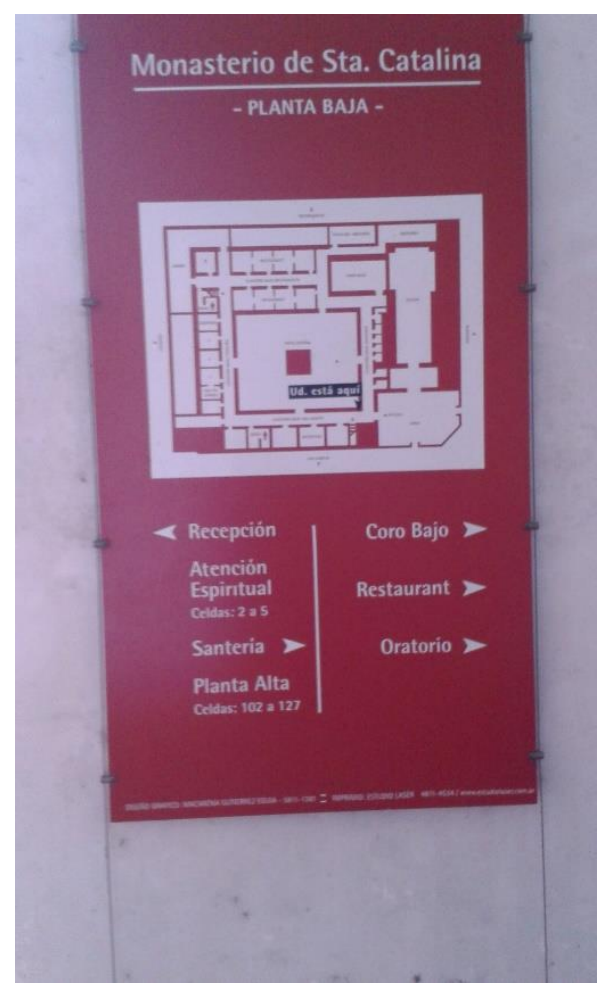

Figura 17: Mapa do Convento de Santa Catalina

Fonte: Acervo dos autores. 


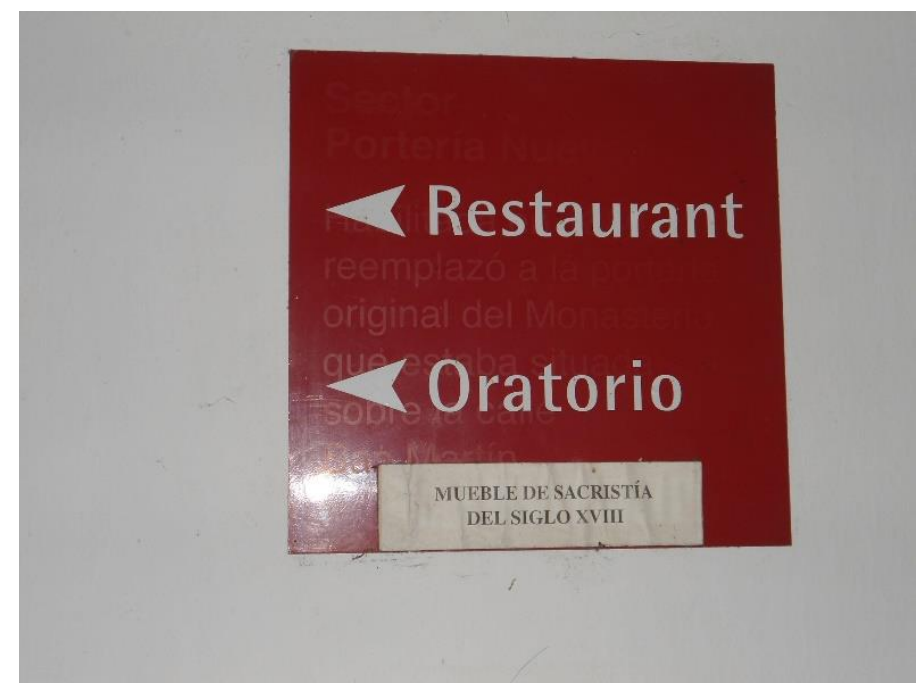

Figura 18: Indicações de acesso aos espaços do Convento de Santa Catalina

Fonte: Acervo dos autores.

A mercantilização da cultura e a necessidade de um vínculo com o desenvolvimento da comunidade

O acesso ao espaço que conforma os Claustros del Pilar, com seus documentos, artefatos, quadros que remontam ao período inicial de funcionamento do convento, é possibilitado a partir do pagamento de um determinado valor. Efetivado o pagamento, o visitante recebe uma espécie de bilhete, cujos dizeres procuram destacar que a quantia arrecadada destina-se à realização de obras sociais na comunidade. 


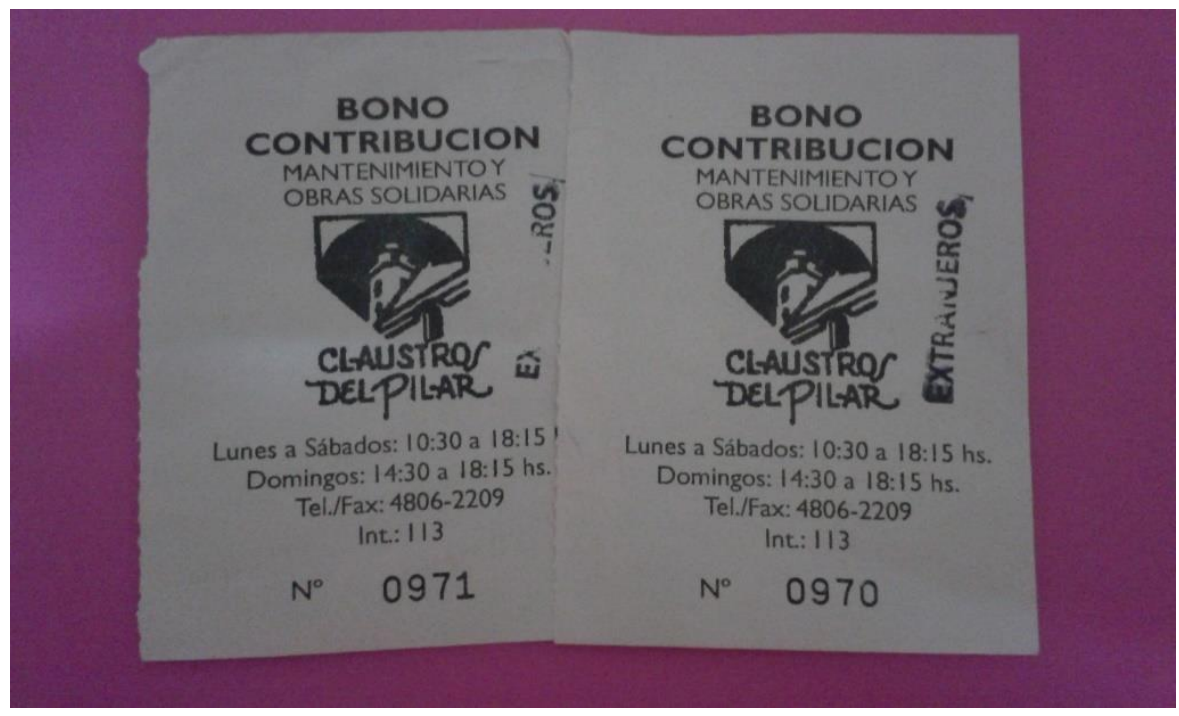

Figura 19: Bilhetes para visitação aos Claustros del Pilar

Fonte: Acervo dos autores.

\section{À GUISA DE CONCLUSÃO}

Neste ensaio fotográfico, a intenção foi representar, mediante um conjunto de fotografias, o argumento de que os espaços sociais do claustro, por meio de seus elementos concretos e simbólicos, são redefinidos e reapropriados de modo a apresentar a ideia da condição de aprisionamento como um produto cultural.

Teoricamente, nosso ponto de partida foi a concepção de lugar como produto social (LEFEBVRE, 1991), como um campo marcado pela dialética entre elementos concretos e simbólicos, e que implica possibilidades várias de ressignificação das ditas ordens material e social de uma espacialidade (CHANLAT, 1996; FISCHER, 1994; GIERYN, 2000).

A questão que procuramos abordar é que estas possibilidades de ressignificação estão atreladas a um movimento urbano de culturalização da economia ou, em outras palavras, da utilização da cultura como instrumento de desenvolvimento dos negócios. Nos termos deste ensaio fotográfico, identificamos, especificamente, a conformação de espaços de claustro em equipamentos culturais como uma estratégia para o desenvolvimento do turismo, considerando que os elementos concretos e simbólicos dos espaços são 
requalificados a partir de uma lógica de consumo, lógica esta ressignificada se considerarmos a finalidade original do Convento de Santa Catalina e dos Claustros del Pilar. Ainda no bojo deste contexto pode-se dizer, precisamente, que a requalificação destes espaços, outrora classificados como instituições totais (GOFFMAN, 1961), alinhase a um processo de patrimonialização e museificação que vem se intensificando, principalmente, nos espaços urbanos, em épocas mais recentes (JACQUES, 2005).

Aspectos que se relacionam ao escopo da arquitetura, gastronomia, artes visuais são redimensionados e sustentam um processo em que os elementos concretos e simbólicos de espaços de claustro são requalificados de maneira a espetacularizar a condição de aprisionamento, típica do cotidiano da maioria das instituições totais. Referimo-nos aqui à espetacularização bem aos moldes da acepção de Debord (1997), que discute a crescente espetacularização da vida e de tudo que é vivido, como as experiências e as vivências dos sujeitos.

No âmbito destes dois espaços sociais, esta espetacularização responde aos interesses e exigências do mercado de turismo. Aliás, a própria nomeação de cada um destes lugares como patrimônio histórico "agrega valor" no contexto da atividade turística. A experiência de estar em um convento, uma espacialidade de refúgio dos que se dedicam à vida religiosa, é uma experiência que pode ser construída, delimitada (existem, por exemplo, os espaços dentro dos conventos que são restritos à visitação) e, principalmente, que pode ser precificada, como qualquer outro produto. Tudo tem um preço, então?

\section{REFERÊNCIAS}

CHANLAT, J. F. O ser humano, um ser espaço-temporal. In: CHANLAT, J. F. (Org.). 0 indivíduo na organização. Dimensões esquecidas. São Paulo: Atlas, 1996. v. 3.

CHOAY, F. A alegoria do patrimônio. São Paulo: UNESP, 2001. 
DEBORD, G. A sociedade do espetáculo: comentários sobre a sociedade do espetáculo. Rio de Janeiro: Contraponto, 1997.

FISCHER, G. N. Espaço, identidade e organização. In: CHANLAT, J. F. (Org.). 0 indivíduo na organização. Dimensões esquecidas. São Paulo: Atlas, 1994. v. 2.

FOUCAULT, M. História da sexualidade: a vontade de saber. 13 ed. Rio de Janeiro: Edições Graal, 1988.

GIERYN, T. F. A space for place in sociology. Annual Review Sociology, Palo Alto, v. 26, p. 463-96, Aug. 2000.

GOFFMAN, E. Manicômios, prisões e conventos. São Paulo: Perspectiva, 1961.

JACQUES, P. B. Errâncias urbanas: a arte de andar pela cidade. ARQTextos, Porto Alegre, n. 7, p. 16-25, 2005.

LEFEBVRE, H. The production of space. Oxford: Blackwell, 1991.

MENEGUELLO, C. Da ruína ao edifício: neogótico, reinterpretação e preservação do passado na Inglaterra vitoriana. São Paulo: Analume, 2008.

STEPHENSON, J. People and place. Planning Theory \& Practice, London, v. 11, n. 1, p. 921, Mar. 2010.

VALADARES, J. C. Qualidade do espaço e habitação humana. Ciência e Saúde Coletiva, Rio de Janeiro, v. 5, n. 1, p. 83-98. 2000. 